\title{
The Effects of Mass Tourism: an Evaluative Study on Cox's Bazar, Bangladesh
}

\author{
Takrima Sayeda \\ Department of Tourism and Hospitality Management, University of Dhaka, Bangladesh
}

\begin{abstract}
Tourism is one of the fastest growing industries in the world. However, the expansion of tourism, mainly mass tourism has potential effects on economy, environment and socio cultural life of a country. Present study mainly examines the extent of mass tourism on the tourist capital of Bangladesh, Cox's Bazar Sadar area. The aim of the study is to describe the positive and negative effects of mass tourism on economy, environment and sociocultural aspects.
\end{abstract}

Keywords: Tourism, Economy, Environment, Socio-Culture, Cox's Bazar

\section{INTRODUCTION}

The tourism industry has emerged as one of the major income driving industries in many developing /middle income countries in the world. According to the statistics of the United Nations World Tourism Organization (UNWTO), International tourist arrival reached a record figure of 1.2 billion in 2015. In terms of the number of tourists, France tops the world's countries list, followed by Spain, USA, China, Italy, UK, Germany, Mexico, Australia and Russia. The recent data available from World Travel and Tourism Council (WTTC), further shows the importance of tourism industry. In 2015, tourism's total contribution to the global economy was $\$ 7.2$ trillion, which was equivalent to 9.8 per cent of total global gross domestic product (GDP). Tourism sector supported 284 million jobs in 2015 that is equal to 1 in 11 of all jobs in the world. International tourism is ranked as the $4^{\text {th }}$ largest industry in the world after fuels, chemicals, and automotive products.

Tourism activities, which began to attract attention after the "Industrial Revolution", became more effective particularly after 1950s. After some countries in the world accomplished the process of industrialization, the members of these countries increased the frequency of their journeys around the world (Ayhan A, 2011). In 1950, just 15 destinations (primarily European) accounted for 98 percent of all international arrivals. By 2015, the figure had fallen to 54 percent (Amin, 2015). It is apparent that the extent of tourism has greatly expanded in recent years to encompassthe developing world. Tourism therefore, came to the forefront during these years, also in Bangladesh like some other countries in the world.

The income from tourism industry received considerable importance because of its contribution to the three high priority goals of any developing countries: generation of income, employment and foreign exchange earnings. When the income gained from tourism activities are considered, the concept of "Mass Tourism" always come forefront. It is defined as a type of tourism in which people can reach holiday facilities or as number of people making journeys and having accommodations together and integrating as a holiday group. It provides leisure activities to a large number of people at the same time and same place. A major part of world tourism income comes from mass tourism.

In recent times, mass tourism has gained a great importance all over the world. Developed countries, along with developing countries have attained a level of economic wealth, which facilitates them to travel easily regardless of their socio economic status. In addition to this, accommodation facilities for different income classes, suitable transportation facilities such as cheap carriers, discovery of new places and last not but the least, the extent of tourism information through the internet have led the spread of mass tourism.

The impacts of mass tourism mainly fall under three fields: economic, socio-cultural and environmental. Definitely the effects of mass tourism could be observed both in the constructive and destructive ways. Even though it incorporates some destructive effects, it is difficult to deny the superiority and the existence of mass tourism for a longer time. Then, the most important thing for nations to avoid from the destructive effects of mass tourism is to undertake strict regulative measures to protect natural environment and historical places and socio-cultural identity of people.

Therefore, the aim of this study is to find out the extent of mass tourism in Bangladesh, especially at the heart of tourism capital of this country, Cox's Bazar. 


\section{STUDY AREA}

Before exploring the study area, let us have a look on Bangladesh. It is a small developing country in South Asia, which is blessed with fascinating natural beauties, ranges from mountains to rivers to beaches to bio-diversity. She boasts the world's largest $125 \mathrm{~km}$ unbroken sandy sea beach sloping down to the blue water of the Bay of Bengal. The Worldwide New 7 Wonders include the Sundarbans (the largest mangrove forest in the world and the home to the Royal Bengal Tiger) and Cox's Bazar, among the more than 440 candidate locations from 220 countries. Despite the potential, the industry is far from booming. Only in recent years, the government seems to have recognized the potential of this industry. According to WTTC, tourism accounted for only 2.2 per cent of GDP in 2016. Total contribution of tourism to GDP in fiscal year 2016 is US\$5.3 billion for Bangladesh, where as it is US\$2,306 Billion for the World. Thus, the industry has grown in a haphazard way in the last decade or so. Emergence of mass tourism and tourism's unplanned growth has damaged the mutual and socio-cultural environments of many tourist destinations. These undesirable side effects have led to the growing concern for the conservation and preservation of natural resources, human well-being and the long-term economic viability of the concerned communities (Akis, Peristinis\& Warner, 1996)

We have chosen Cox's Bazar Sadar as our study area as it is the tourism capital of Bangladesh. Cox's Bazar Sadar is under the Cox's Bazar district, which is located in Chittagong Division. The total area of Cox's Bazar Sadar is $228.23 \mathrm{sq} \mathrm{km}$, located in between $21^{\circ} 24^{\prime}$ and $21^{\circ} 36^{\prime}$ north latitudes and in between $91^{\circ} 59^{\prime}$ and $92^{\circ} 08^{\prime}$ east longitudes. It is bounded by Chakaria upazila on the north, Bay of Bengal and Ramu upazila on the south, Ramu upazila on the east, Maheshkahli upazila, Maheshkhali channel and Bay of Bengal on the west.

\section{STUDY DESIGN}

Present study is a descriptive one drawing on empirical data and a wide range of literature from various sources. The desk research method has been followed to review the existing literature. The study is a theoretical analysis of secondary data.Besides, informal interview method was followed to discuss with local people, experts of tourism industry and the administrative officials of some service providing organization in Cox's Bazar spot.

\section{FINDINGS AND DISCUSSION}

The findings of the study have two segments. The first segment encompasses the tourism potential and the second segment ascertains the effects of mass tourism in the study area.

\subsection{Tourism Potential of Cox's Bazar}

Cox's bazar is one of the most attractive places of Bangladesh in terms of its natural beauty. It is regarded as the tourist capital of Bangladesh. The most important one is the world's longest $125 \mathrm{~km}$ unbroken sandy sea beach sloping down to the blue water of the Bay of Bengal, which mainly attracts tourists here in Cox's Bazar. The warm shark free waters are good for bathing and swimming, while the sandy beaches offer the opportunities of sun bathing. The towering cliffs, water streams, surfing waves and marine drive follow this. The attractive religious values of the area are colorful pagodas and Buddhist temples. The local variety of cigars, clothing and food culture of Rakhyne tribal families are other components that contribute to the tourism in this area. Other than the beach, there are several places of interest situated near the town, which can be easily visited from the town center, makes the town a hub of tourism. Keeping the Cox's Bazar Sadar as the epicenter, visits to the mesmerizing spots at Inani, Himchori, Teknaf, Buddist temple at Ramu, islands of Sonadia and Maheshkahli and last not the least coral island of Saint Martin can make a memorable experience of a lifetime.

\subsection{The Effect of Mass Tourism}

The spread of mass tourism dates back to the time when the industrial revolution was completed in western countries. Industrialization, along with transportation facilities, economic development and technological advancement facilitated the middle class of world population to enhance their tourist activities. After 1980s, together with changes in organizations, air travels available to greater parts of population made it easier for large masses to make vacation journeys to distant places (Ayhan, A, 2011).

Mass tourism in Cox's Bazar area has brought many consequences. These consequences can be examined under two segments: Positive and Negative. The advancement of mass tourism leads to economic growth. The income received from tourism, when used for development of infrastructural facilities, can further promote tourism and economic growth. Tourism can contribute to alleviate poverty by creating jobs for marginalized, disadvantaged and unskilled group of people through proper training. The negative effects can be environment pollution, eruption of the coastlines, overuse of water resources, traffic congestion and unplanned growth of high raised buildings. Thus, the overall effects of mass tourism on Cox's Bazar can be evaluated under the three broad headings. 


\subsubsection{Economic Impact of Tourism}

Contribution to GDP: Economic impact of tourism can be described in various ways. Tourism sector synchronously contributes to three high priority goals of any developing countries: income, employment and foreign exchange earnings. These contributionscan be seen as multiplier concept through direct, indirect and induced effect. The first tier of tourism recipients comprises the spending by the tourists on hotels, restaurants, leisure industries, are called direct effect. These direct activities depend on other activities for operational purpose. The indirect effects of tourism concern all sectors of the economy, especially agriculture, food industries and all tourism related services. The changes in economic activities resulting from household spending of income earned directly or indirectly as a result of tourism spending are called induced effect. It can be seen in figure 1 and figure 2 .

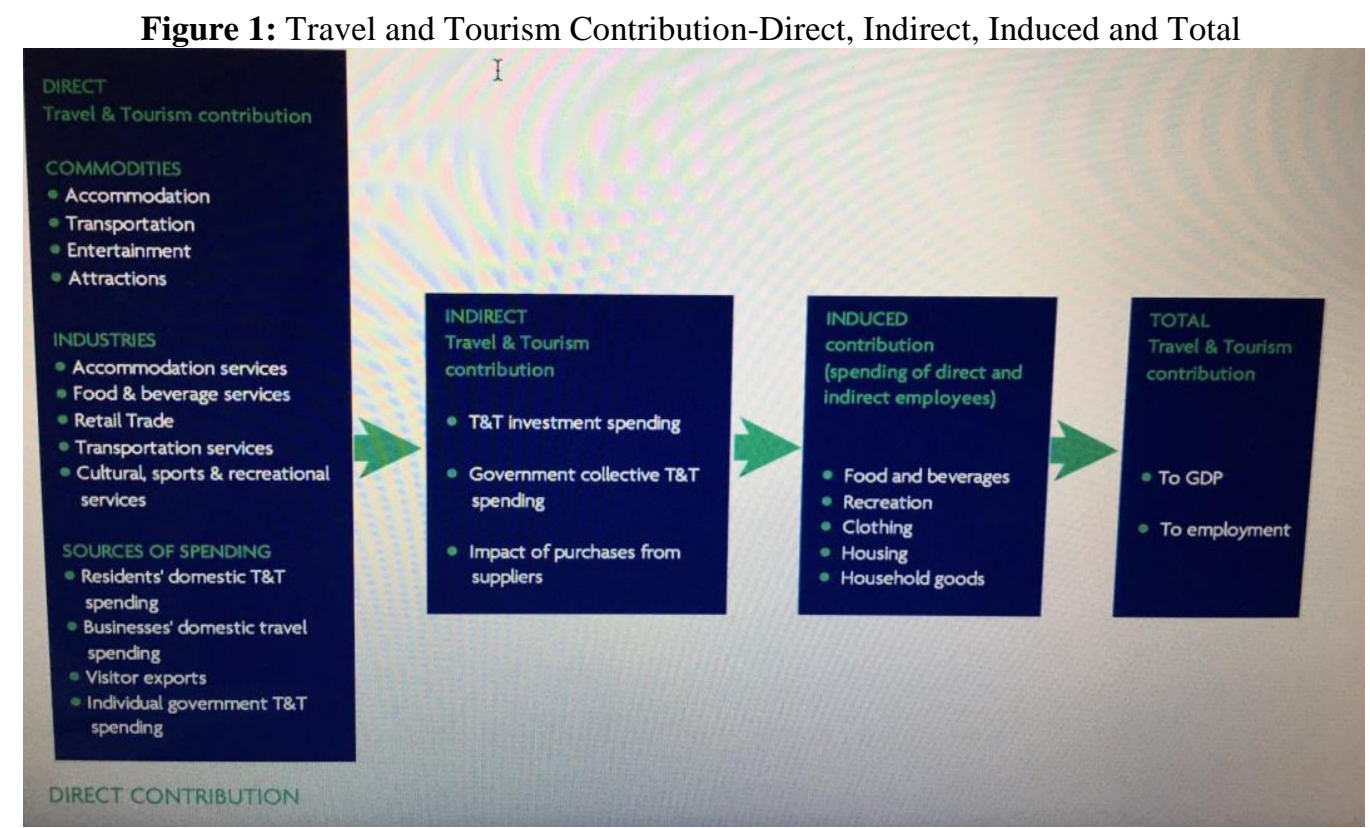

Source: Travel and Tourism Economic Impact 2017, Bangladesh, WTTC

In terms of these three effects, direct effects constituted largest contribution (i.e., $2.2 \%$ of GDP), followed by indirect effect of around $1.4 \%$ and induced effect $0.9 \%$ of GDP. (TSA 2011-12).

Figure 2: Contribution of Travel and Tourism to GDP and Employment

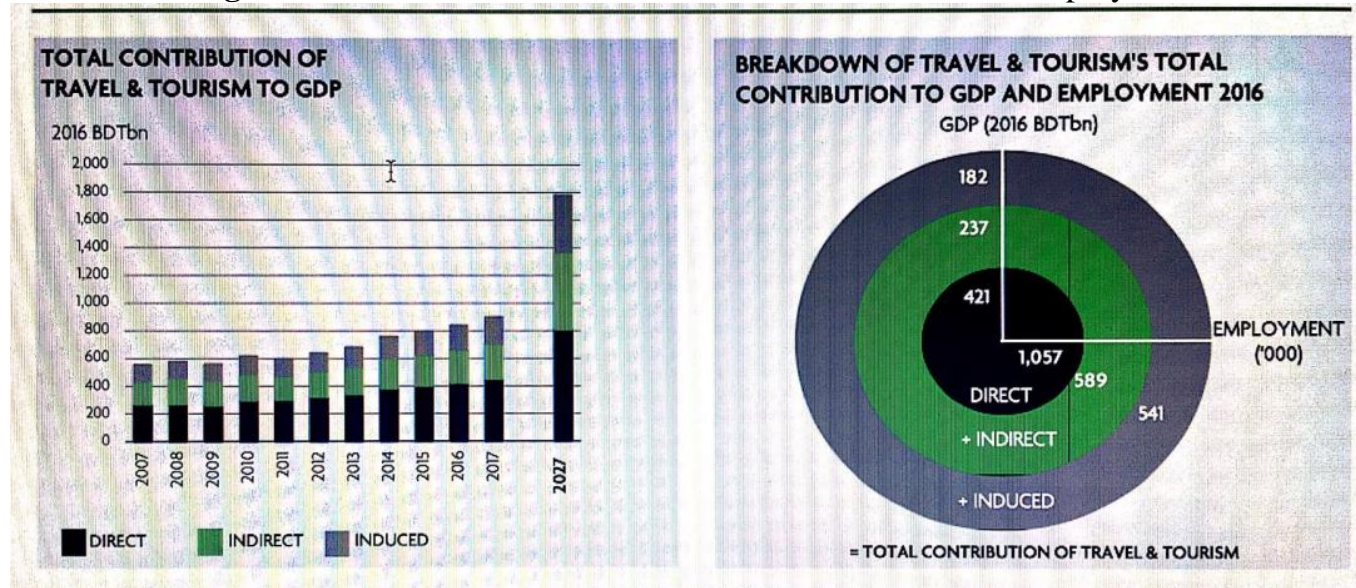

Source: Travel and Tourism Economic Impact 2017, Bangladesh, WTTC

Contribution to Employment: Mamun, Hasan and Hossian(2013) reported some empirical data on their paper. It says, there are 220 hotels and guest house in Cox's Bazar and each employs on an average 20 people thus the total count is 4400. In case of restaurants for food supply, Cox's Bazar has 154 restaurants, which employs on an average 22 assistants and the total count is 3388 persons. Again Cox's Bazar registers 54 tour operators and guide houses, in which on an average 15 persons work in each company and the total figure is 810 
persons. As the infrastructure of hotels and touristy activities are going on, on an average 5000 construction workers are working in that vicinity. Many local people are involved in tourism related activities. They are working as tourist guides, junk business, rent -a-car business, land business, opening departmental stores, selling souvenir, hiring umbrella on the sea beach, driving small playing vehicles on the beach and so on. A large number of people are also involved in fishing and collecting seafood and sea products for their livelihood. As tourism industry is labor intensive and supports diverse labor market, it offers a wide range of job opportunities both for unskilled and skilled workers.

Number of tourist arrival: The economic contribution of tourism and the share of Cox's Bazar to the national economy have not been studied with reliable statistics. Therefore, it will be difficult to assess the actual economic contribution of Cox's Bazar as a tourist destination. However, according to Ahammed(2010), nearly two million people visit Cox's Bazar in peak season from November to March. The beaches of Laboni, Kolatoli, Himchori and Inani are heavily visited. Reportedly, Laboni beach is one of the most heavily visited tourist destination in the country, with daily maximumvisitors as high as 30,000 (Ahammed 2010).

Therefore, from the general observation, it is understandable that tourism has brought a big change in the Cox's Bazar area in terms of income, employment and growth.

\subsubsection{Environmental effects of mass tourism}

Though tourism can sustain high levels of employment and income in the economies of many regions, many tourist destinations around the world are still struggling to overcome the detrimental effects they suffered from the rapid and uncontrolled expansion of mass tourism and short term profit oriented mentality (Dimitriou, 2017). Russo(2001) placed a notification against the vicious circle of tourism development and environmental degradation. Li and Yang (2007) found that tourists might leave a significantly larger ecological footprint than local people who still lived with subsistence conditions.

Traffic Congestion: The mass tourism has brought some significant changes in the urban structure of the Cox's Bazar town. There are many touristic hotels in the town center. Thus the possible pressure on the center has been high. Mainly, at every weekend the entry point of Cox's Bazar town has been crowded with inter highway buses from $6 \mathrm{pm}$ to $11 \mathrm{pm}$. Thus, the heavy vehicle at the entry point and pedestrian traffic in beach area is common phenomenon of this area. Dwelling demand for migrant workers: Another pressure comes from dwelling demands of the immigrant workers. Upsurge of tourism creates employment opportunities, which in turn causes migration from nearby areas to the township. To meet the excessive dwelling demand, some unplanned urbanization has been created in the city.

The effects of tourism on water usages: Several studies demonstrate that the viability and sustainability of any tourist destination is ultimately dependent upon an adequate water supply, both in quantity and quality (Essex et al., 2004; Kent et al., 2002). Disparity in water consumption between tourists and the local population is an ever-increasing problem and, whatever the complexity of quantifying water consumption by the tourism sector, tourist water consumption is between two and three times that of local water demand in developed countries (Garcia and Servera, 2003) and up to 15 times the water consumption in developing countries (Gössling, 2001). It has been estimated by Tourism Concern that local resident's average local water consumption is around 201 per day. However, the figures for Goa suggest that whilst local residents consume 14 1 per person per day, the tourists consume, on average, 17851 of water per day (Tourism Concern, 2012). According to Ecologic (2007), significant differences can be observed in water consumption depending on the type of lodging: hotels of different categories, campsites, holiday lets, bed and breakfast guesthouses, resort hotels etc, and tourist activities during the stay: yachting golf, swimming etc. Hotels and holiday houses consume far more water (394 1 per overnight stay- hereafter 1/os), than campsites (174 1/0s), and typically this consumption is candidly related to the category.

Though there have not been any studies regarding the water consumption in Cox's Bazar area, it is apparent the excessive water usage is a mere reality to mitigate the demand for mass tourist. Many of the hotels and tourist attractions in Cox's Bazar depend on ground water as their water supply. The over withdrawal of groundwater has negative impact and can cause land subsidence. In dry season, when the water level goes down, the tourist attraction facilities face severe water scarcity. Moreover, over exploitation of groundwater in Cox's Bazar increases by the tourists and regular habitat causes salinity problem in the shallow aquifer. Due to human induced activities the salt water front is encroaching towards the land and the natural stabilization becomes imbalanced (Ahmed, 2010)

The effect of tourism on solid waste management: According to Holden (2008), one of the most important impacts of tourism is the generation of municipal solid waste (MSW). Tourism and urbanization generates direct and indirect solid waste impacts. This problem has multifaceted direction as Cox's Bazar faces difficulties arranging solid waste disposal facilities. Paurashava (City Corporation) waste disposal site is located in highly spongy soils adjacent to Bakkhali River, which leads to ground water and surface water contamination. Some tourist resorts empty their sewage and other wastes directly into water surrounding coral reefs and other sensitive marine habitats. Many of the land plots, which are underdeveloped or waited to be developed as hotel/ 
resort in near future, have been using as solid waste landfills. In one hand these sites pollute the aesthetics of the adjacent area, on the other hand it is becoming one of the great threats in ground water contamination. Ground water is contaminated due to human usage as the ground water and waste disposal more or less interact at the same level of soil layer. Non-existent or improperly operated sewerage systems at hotels and resorts are major contributors to this problem.

Physical changes and habitat damage:According to the Third Assessment of Europe's Environment (EEA 2003), one of the results of the direct impact of tourism is the change in the landscape coming from the construction of infrastructure, buildings and facilities. The beach area ranges from Cox's Bazar to Teknaf has been already taken for construction of hotels and resorts. Construction along the beach continuously changes the beach morphology by the construction activities like dredging, sand removal, and destruction of mangrove forests. Sea grass meadows have been removed to create open beaches. The damage doesn't end with the construction of tourist infrastructure. Recreational activities have a huge impact. For example, careless motor riding in the beach, diving and fishing have substantially damaged corals in the beach area, through touching corals, stirring up sediments and dropping anchors. Nesting sites for endangered marine turtles have been destroyed and disturbed by large numbers of tourists on the beaches. Seafood consumption is another attraction of tourism in Cox's Bazar area. However, it eventually adds pressure on local fish populations and some times contributing to overfishing. Collection of corals, shells and other marine souvenirs-either by individual tourist, or local people who sell the souvenirs to tourists- also has a detrimental effect on the local environment (Coastalwiki.org).

\subsubsection{Socio Cultural effects of mass tourism}

Tourism has significant effects on cultural elements in Cox's Bazar. Considering tourism from socio cultural perspective, it affects traditional life style, changes in occupational types, income inequality, and local values. According to Ahammed(2010), literacy rate is increasing and traditional popular belief or superstition or even profession is being replaced by the mixing of the tourists who have a fair understanding of modern ideas. Living standard of the community is increasing and they receive the tourist and tourism with welcoming attitudes. Income generated from touristic activities mainly facilitates ranges of development works and infrastructural activities. The cultural exchange between the host and the tourist results in changing traditional life style: ranges from clothing, language, food and growing openness in terms of mixing and learning from the tourists. However, there are some untoward developments in sociocultural aspects due to mass tourism. Tourism can turn local culture into commodities when religious traditions, local customs and festivals are reduced to conform to tourist expectations. Social instability is growing over harnessing the benefit of tourism. As a result, crime rate is getting higher unexpectedly. Cultural clashes may arise due to income inequality between locals and tourists, who are spending more at tourist spot than at home. Sometimes, out of ignorance or carelessness, tourists fail to respect local customs and moral values, which in turn infuriated the locals. Apart from these, due to lack of professional training, many low-paid tourism-jobs go to local people while higher paying and more prestigious managerial jobs go to foreigners or "urbanized" nationals, create job level friction.

\section{CONCLUSION}

Tourism is regarded as a potential stimulus to the economies in recent decades. It can sustain high levels of employment and income. In 2015, 1.2 billion tourists traveled outside their borders, generating revenues of \$7.2trillion, which was equivalent to 9.8 per cent of total global gross domestic product (GDP). Tourism can contribute to the three priority goals of any developing countries: generation of income, employment and foreign exchange earnings. Through the multiplier effect, the tourism led growth can occur and people can reap the benefit with improved living standards. However, this mass tourism is not without disadvantages. The impacts of tourism, on the environment, economic, social and cultural life, are often detrimental. The current study focuses on the effects of mass tourism in Cox's Bazar Sadar Area, known as the tourist capital of Bangladesh.

The effect of mass tourism on economic perspective is favorable, ample employment opportunities are continuously created for the unskilled and marginalized workers in the tourism sector. This upsurge in job creation ultimately generates demand through income generation. Additionally, the income generated from the tourists can be further used to the development of the local area. In contrast to the economic aspects, environmental and socio-cultural aspects of Cox's Bazar found to be less favorable. The extent of traffic congestion, overuses of water resources, improper solid waste management are not taken care of properly. Buildings are made adjacent to the beaches, which are causing impediments to natural environment and the spoiling the beauty of the sea.

Tourism has significant effects on socio-cultural elements in Cox's Bazar. Considering tourism from socio cultural perspective, it affects traditional life style, changes in occupational types, income inequality, and local values. 
According to Shaw and Williams (2009), it is possible to prevent negative outcomes and promote positive outcomes through sustainable development as it can protect the over all environment of a destination. A welldesigned tourism policy is of immense importance for combating the detrimental effects of mass tourism. To achieve a sustainable tourism in Cox's Bazar area, environmental concerns are to be prioritized and the socio cultural imbalances are to be prevented. However, the local authorities, tourism sector and tourists need to be harmonized in a tandem to overcome the adverse effects of mass tourism in Cox's Bazar area.

\section{REFERENCE}

[1]. United Nation World Tourism Organization (UNWTO).http://www2.unwto.org/content/why-tourism.

[2]. World Travel and Tourism Council (WTTC). https://www.wttc.org//

[3]. AyhanAkis, The effects of mass tourism: A case study from Manavgat (Antalya-Turkey), The $2^{\text {nd }}$ International Geography Symposium GEOMED 2010, Procedia Social and Behavioral Sciences 19(2011) 289-296

[4]. Amin, Sakib bin, The economy of tourism in developing world. https://www.academia.edu/27100831/The_Economy_of_Tourism_in_the_Developing_World

[5]. Akis, S., Peristianis, N., \& Warner, J., Residents' attitudes to tourism development: The case of Cyprus, Tourism Management, 17, 1996, 481-494

[6]. Tourism Satelite Account (2011-2012) http://203.112.218.65/WebTestApplication/userfiles/Image/National\%20Account\%20Wing/Report/Touri smSatellite.pdf

[7]. Mamun, Mohammad Abdullah Al., Hasan, Md. Kamrul.,Hossain, Sheikh A.K. Mohsinul., Image of Cox's Bazar Beach as a Tourist Destination: An Investigation, International Review of Business Research Papers, 9(5) 2013, 122-138.

[8]. Ahammed, Sheikh Saleh.,Impact of Tourism in Cox's Bazar, Bangladesh, Master Thesis, Master in Public Policy and Governanace Program, Department of General and Continuing Education, North South University, Bangladesh.

[9]. Dimitriou, Christina K., The quest for a practical approach to mortality and the tourism, Journal of Hospitality and Tourism Management, 31(2017), 45-51.

[10]. Russo, A. P., The "vicious circle" of tourism development in heritage cities. Annals of Tourism Research 29 (2001), 165-182.

[11]. Li, P., Yang, G., Ecological footprint study on tourism itinerary products in Shangri-La, Yunnan Province, China, ActaEcologiaSinica 27 (2007), 2954-2963.

[12]. Essex, S., Kent, M., \&Newnham, R., Tourism development in Mallorca, Is water supply a constraint? Journal of Sustainable Tourism, 12 (1) 2004, 4-28.

[13]. Kent, M.Newnham, R., \& Essex, S., Tourism and sustainable water supply in Mallorca: A geographical analysis, Applied Geography, 22 (4), 2002, 351-374.

[14]. Garcia, C., \&Severa, J., Impacts of Tourism Development on Water Demand and Beach Degradation on the Island of Mallorca (Spain), GeografiskaAnnaler: Series A, Physical Geography, 85(3-4), 2003, 287300 .

[15]. Gössling, S., The consequences of tourism for sustainable water use on a tropical island: Zanzibar, Tanzania, Journal of Environmental Management, 61(2), 2001, 179-191.

[16]. Tourism Concern, https://www.tourismconcern.org.uk/water-equity-in-tourism/

[17]. Ecologic, Final Report. EU Water Saving Potential (Part 1eReport) ENV.D.2/ ETU/2007/0001r. Institute for International and European Environmental Policy (2007)

[18]. Ahmed, SamanUddin.,Assessment of groundwater resources and impacts of tourism on groundwater of Cox's Bazar town, Bangladesh, Masters Thesis, Department of Geology, University of Dhaka.

[19]. Holden, A., Environment and Tourism, Routledge 2 (2008), Abingdon.

[20]. EEA 2003, http://reports.eea.europa.eu/environmental_assessment_report_2003_10/en

[21]. Coastalwiki.org, http://www.coastalwiki.org/wiki/Impact_of_tourism_in_coastal_areas:_Need_of_sustainable_tourism_str ategy

[22]. Shaw, S., \& Williams, A. M., Knowledge Transfer and Management in Tourism Organisations: an emerging research agenda, Tourism Management 30 (3), 2009, 325-335. 